\title{
Effect of Fatigue Damage on Energy Absorption Properties of Honeycomb Paperboard
}

\author{
Zhi-geng Fan, ${ }^{1,2}$ Li-xin Lu, ${ }^{1,3}$ and Jun Wang ${ }^{1,3}$ \\ ${ }^{1}$ Department of Packaging Engineering, Jiangnan University, Wuxi 214122, China \\ ${ }^{2}$ School of Light Industry, Zhejiang University of Science and Technology, Hangzhou 310023, China \\ ${ }^{3}$ Jiangsu Key Laboratory of Advanced Food Manufacturing Equipment and Technology, Wuxi 214122, China
}

Correspondence should be addressed to Li-xin Lu; lulx@jiangnan.edu.cn and Jun Wang; wangj_1982@jiangnan.edu.cn

Received 28 September 2014; Accepted 10 December 2014

Academic Editor: Katsuhiko Saito

Copyright (C) 2015 Zhi-geng Fan et al. This is an open access article distributed under the Creative Commons Attribution License, which permits unrestricted use, distribution, and reproduction in any medium, provided the original work is properly cited.

\begin{abstract}
The effect of fatigue damage (FD) on the energy absorption properties of precompressed honeycomb paperboard is investigated by fatigue compression experiments. The constitutive relations of honeycomb paperboard have been changed after the fatigue damage. The results show that FD has effect on plateau stress and energy absorption capacity of honeycomb paperboard after fatigue cycles but has no significant effect on densification strain. Energy absorption diagram based on the effect of FD is constructed from the stress-strain curves obtained after fatigue compression experiments. FD is a significant consideration for honeycomb paperboard after transports. The results of this paper could be used for optimization design of packaging materials.
\end{abstract}

\section{Introduction}

Honeycomb paperboard is a kind of widely used packaging material. Energy absorption diagrams are a method to evaluate the cushioning properties of cushioning materials, and it has been reported as being successfully applied to plastic foams and aluminum alloy material [1]. Many researchers [2-5] have studied the cushioning properties and energy absorption property of honeycomb paperboard.

Guo and Zhang [6] tested the shock absorbing characteristics and vibration transmissibility of honeycomb paperboard. The honeycomb paperboard system is a nonlinear packaging system. In recent years, Wang et al. [7] establishedthe three-dimensional shock spectrum of critical component for nonlinear packaging system. Chen [8] studied the shock characteristics of tilted support spring packaging system with critical components.

The problem is that there is an initial peak stress at the end of the elastic stage, which is harmful to the protective packaging. In the past years, many researchers [9-11] have found that the precompression could suppress the initial peak stress and they have studied the cushioning properties of precompressed honeycomb paperboard.
Sun $[12,13]$ analyzed the load capacity and S-N curve of the corrugated paperboard. Rouillard et al. $[14,15]$ monitored the evolution of fatigue damage of corrugated paperboard in packaging systems under sustained random loading. Fan and $\mathrm{Lu}$ [16] analyzed the effect of fatigue damage on innerresonance conditions of precompressed honeycomb paperboard system.

Though the protective performance of honeycomb paperboard has been thoroughly studied, few works on the performance of precompressed honeycomb paperboard were reported in literature, especially on the effect of fatigue damage on energy absorption properties of honeycomb paperboard.

The aims of this study are to

(a) examine the effect of FD on the energy absorption properties of honeycomb paperboards with varying thickness-to-length ratios,

(b) establish energy absorption diagram based on the effect of FD for honeycomb paperboard with different configurations. 
TABLE 1: Characteristics of honeycomb paperboard specimens.

\begin{tabular}{lcccccc}
\hline Specimens & $\begin{array}{c}\text { Height } \\
(\mathrm{mm})\end{array}$ & $\begin{array}{c}\text { Basis weight of } \\
\text { corrugated medium } \\
\left(\mathrm{g} / \mathrm{m}^{2}\right)\end{array}$ & $\begin{array}{c}\text { Basis weight of } \\
\text { liner } \\
\left(\mathrm{g} / \mathrm{m}^{2}\right)\end{array}$ & $\begin{array}{c}\text { Thickness of } \\
\text { corrugated medium } t \\
(\mathrm{~mm})\end{array}$ & $\begin{array}{c}\text { Cell length of } \\
\text { honeycomb } l \\
(\mathrm{~mm})\end{array}$ & $\begin{array}{c}\text { Thickness-to-length } \\
\text { ratio } t / l\end{array}$ \\
\hline PA-105AB/200A & 40 & 105 & 200 & 0.19 & 7.22 & 0.0263 \\
PA-105B/200A & 40 & 105 & 200 & 0.19 & 7.98 & 0.0238 \\
PA-105C/200A & 40 & 105 & 200 & 0.19 & 8.66 & 0.0219 \\
\hline
\end{tabular}

TABLE 2: Plateau stress of honeycomb paperboard after FD $\left(23^{\circ} \mathrm{C}\right)$.

\begin{tabular}{|c|c|c|c|c|c|}
\hline \multirow{2}{*}{$\begin{array}{l}\text { Thickness-to-length } \\
\text { ratio } t / l\end{array}$} & \multicolumn{5}{|c|}{ Plateau stress $(\mathrm{MPa})$} \\
\hline & $n=0$ & $n=10000$ & $n=20000$ & $n=30000$ & $n=50000$ \\
\hline 0.0263 & 0.1164 & 0.1063 & 0.0945 & 0.0835 & 0.0786 \\
\hline 0.0238 & 0.0982 & 0.0916 & 0.0815 & 0.0713 & 0.0682 \\
\hline 0.0219 & 0.0732 & 0.0684 & 0.0623 & 0.0565 & 0.0534 \\
\hline
\end{tabular}

\section{Experimental Materials and Methods}

The specimens of honeycomb paperboards were supplied by the professional manufacturing industry of HONICEL Honeycomb Material Group (Changshu, Suzhou, China). The specifications and characteristics of specimens are listed in Table 1.

The experiments were conducted at China National Light Industry Package Quality Supervising \& Testing Center. The test equipment included a temperature humidity programmable controller (THS-A7C-100AS) and a universal material testing machine (LRX Plus, full-scale load range of $5 \mathrm{KN}$, LRX Systems Co., Ltd.) and an electrohydraulic servo testing machine (MTS322, MTS Co., Ltd.).

The test standards included GB/T 1040.1-2006 PlasticDetermination of tensile properties, part 1: general principles, GB/T 8168-2008 [17] testing method of static compression for package cushioning materials, GB/T 1453-2005 test method for flatwise compression properties of sandwich constructions or cores, and the ISO 2233-1986 Packaging-Transport Packages-Temperature and Humidity Conditioning.

The dimension of specimen was made of $100 \mathrm{~mm} \times$ $100 \mathrm{~mm}$. All samples were first preconditioned for 24 hours in $23^{\circ} \mathrm{C}, 50 \% \mathrm{RH}$. After that, the samples were precompressed $15 \%, 20 \%, 25 \%, 30 \%$, and $40 \%$ strain ratio test with a constant rate of $12 \mathrm{~mm} / \mathrm{min}$, after which the specimens were placed in storage environment for 2 hours to fully release the compression stress and then divided into three groups and conducted $10 \%$ strain ratio fatigue compression test for $n=0,10000$, 20000, 30000, and 50000 cycles separately. Finally, the specimens after all tests above were compressed separately with a constant rate of $12 \mathrm{~mm} / \mathrm{min}$. Strain ratio means nominal strain and $40 \mathrm{~mm}$ height is used as the initial length of specimens to calculate strain ratio even if the permanent strain exists.

The strain and stress data in each test were recorded by an automatic data acquisition and then were converted to stress versus strain curves by executing MATLAB [MATLAB R2007, The Math Works, Inc.] program. The stress-strain curves were used to analyse the mechanical behaviors of corrugated medium and the energy absorption properties of honeycomb paperboard under five levels of FD.

\section{Results and Discussion}

3.1. Mechanical Behavior of Honeycomb Paperboard as Response to FD. Figure 1 shows the stress-strain curve of the honeycomb paperboards precompressed $15 \%$ strain ratio, and all samples conducted $10 \%$ strain ratio fatigue compression test for $n=0,10000,20000,30000$, and 50000 separately. According to Figure 1, the initial peak stress disappeared. The compression stress-strain curve of precompressed honeycomb paperboard has three stages, which includes the elastic, plateau, and densification stages.

Plateau stress of honeycomb paperboard is the average value of the plateau stages.

It can be seen from Table 2 that the plateau stress can be divided into two stages demarcated by $n=30000$. The plateau stress is sensitive to FD from $n=0$ to 30000 and FD has no significant effect on plateau stress from $n=30000$ to 50000. For example, the plateau stresses of three kinds of honeycomb paperboards (AB-type, B-type and C-type, resp.) tested from $n=0$ to 30000 decreased by $29.3 \%, 27.5 \%$, and $23.2 \%$, respectively; the plateau stress decreased significantly with the increasing of FD. Taking honeycomb paperboard with the thickness-to-length ratio of 0.0263 , for example, its plateau stress at $n=50000$ decreased by $4.87 \%$.

Densification strain is the ratio of the maximum height reduction to the initial height of honeycomb cell during the crush process.

According to Table 3, densification strain is the ratio of the maximum height reduction to the initial height of honeycomb cell during the crush process. It can be concluded that FD has no significant effect on the densification strains as well as various humidity [18].

Experiment results under five levels of FD can be averaged and be taken as the densification strain of this honeycomb type: $t / l=0.0263$ and $\varepsilon_{D}=0.7582 ; t / l=0.0238$ and $\varepsilon_{D}=$ $0.7673 ; t / l=0.0219$ and $\varepsilon_{D}=0.7808$. 


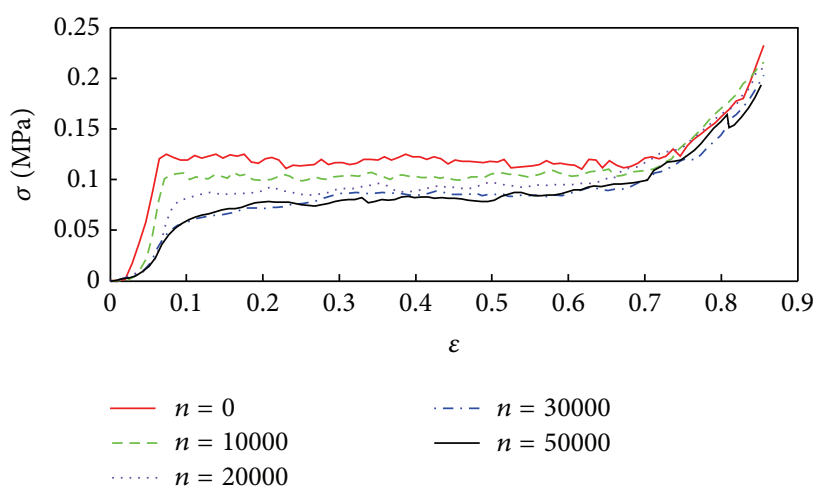

(a)

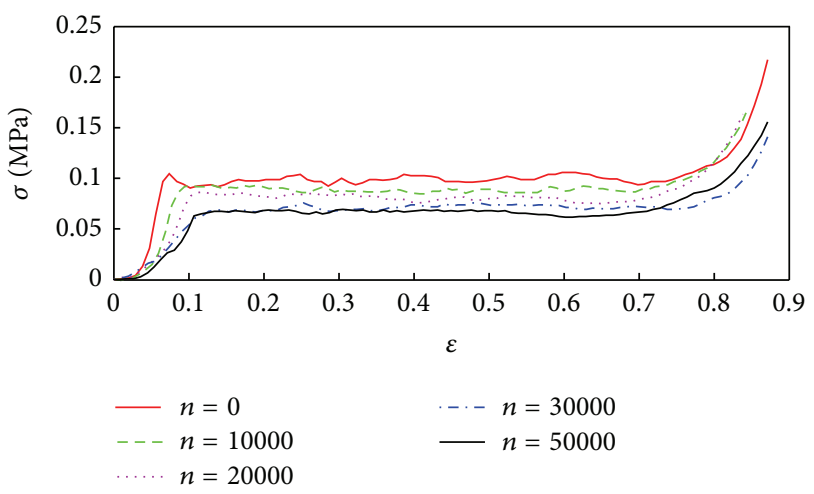

(b)

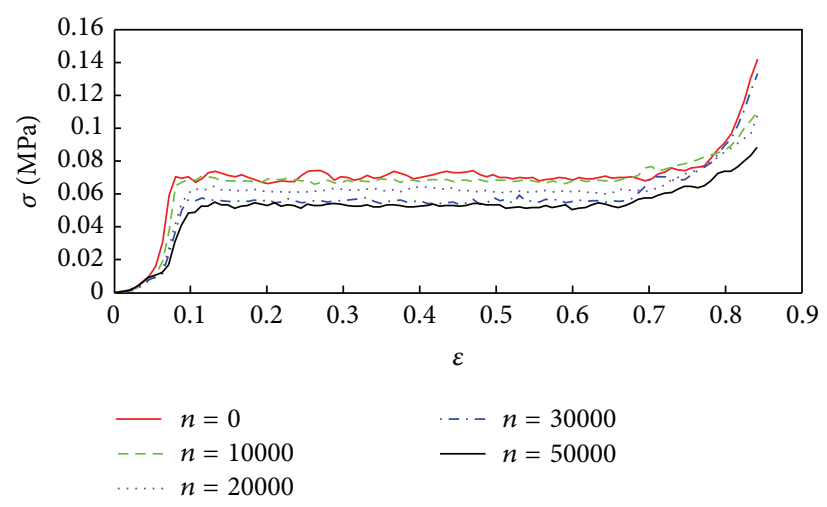

(c)

FigURE 1: Effect of fatigue stress-strain relationship of precompressed (15\% strain ratio) honeycomb paperboard (a) $t / l=0.0263$, (b) $t / l=$ 0.0238 , and (c) $t / l=0.0219$.

TABLE 3: Densification strains of honeycomb paperboard under various FD $\left(23^{\circ} \mathrm{C}\right)$.

\begin{tabular}{lccccc}
\hline $\begin{array}{l}\text { Thickness-to-length } \\
\text { ratio } t / l\end{array}$ & $n=0$ & $n=10000$ & $\begin{array}{c}\text { Densification strain } \varepsilon_{D} \\
n=20000\end{array}$ & $n=30000$ & $n=50000$ \\
\hline 0.0263 & 0.754 & 0.763 & 0.756 & 0.757 & 0.760 \\
0.0238 & 0.762 & 0.771 & 0.765 & 0.769 & 0.768 \\
0.0219 & 0.782 & 0.778 & 0.783 & 0.778 & 0.783 \\
\hline
\end{tabular}

Figure 2 shows the stress-strain curves of the honeycomb paperboards $(t / l=0.0263)$ precompressed $15 \%, 20 \%, 25 \%$, $30 \%$, and $40 \%$ strain ratio, and all specimens conducted $10 \%$ strain ratio fatigue compression test for $n=0,10000,20000$, 30000 , and 50000 separately. It can be also seen that precompression has no significant effect on the densification strains.

It can be seen from Table 4 that the plateau stress can also be divided into two stages demarcated by $\varepsilon=25 \%$. The plateau stress is sensitive from $\varepsilon=15 \%$ to $\varepsilon=25 \%$ and FD has slight effect on plateau stress from $\varepsilon=25 \%$ to $\varepsilon=40 \%$. For example, the plateau stresses of honeycomb paperboard $(t / l=0.0263)$ from $\varepsilon=15 \%$ to $\varepsilon=25 \%$ under various $\mathrm{FD}$ decreased by $21.5 \%, 21.6 \%, 20.1 \%$, and $21.9 \%$ respectively; the plateau stress decreased significantly with precompression increasing. But its plateau and plateau stress from $\varepsilon=25 \%$ to $\varepsilon=40 \%$ decreased by $12.1 \%, 12.9 \%, 14.4 \%$, and $10.7 \%$.
3.2. Energy Absorption Property of Honeycomb Paperboard as Response to FD. The effect of FD on the energy absorption property of honeycomb paperboard is investigated from different aspects, including efficiency, energy absorption per unit volume, and ideality of energy absorption curves [18]. In this paper, honeycomb paperboard is investigated from efficiency, energy absorption curves, and energy absorption per unit volume. Efficiency $(E)$ is an indicator to characterize the energy absorption performance of packaging material and can be computed by the formulas as follows:

$$
E=\frac{\int_{0}^{\varepsilon_{p}} \sigma d \varepsilon}{\sigma_{p}}
$$

where $E$ is efficiency, $\varepsilon_{p}$ represents static strain, and $\sigma_{p}$ represents static stress. 


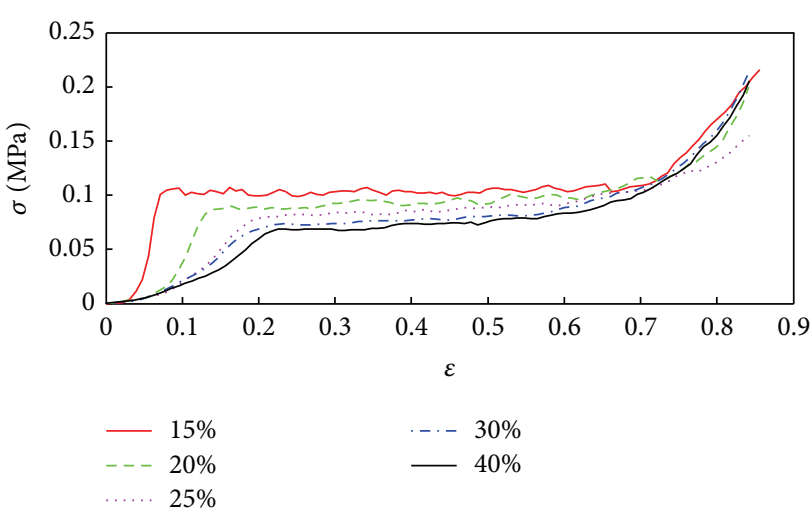

(a)

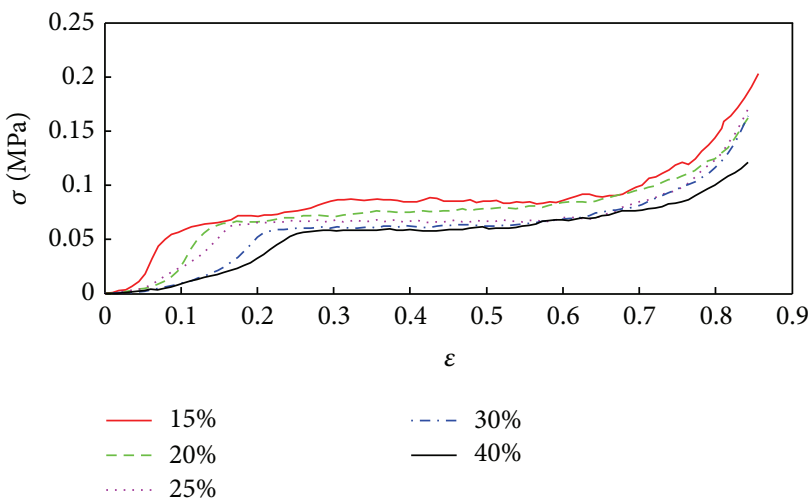

(c)

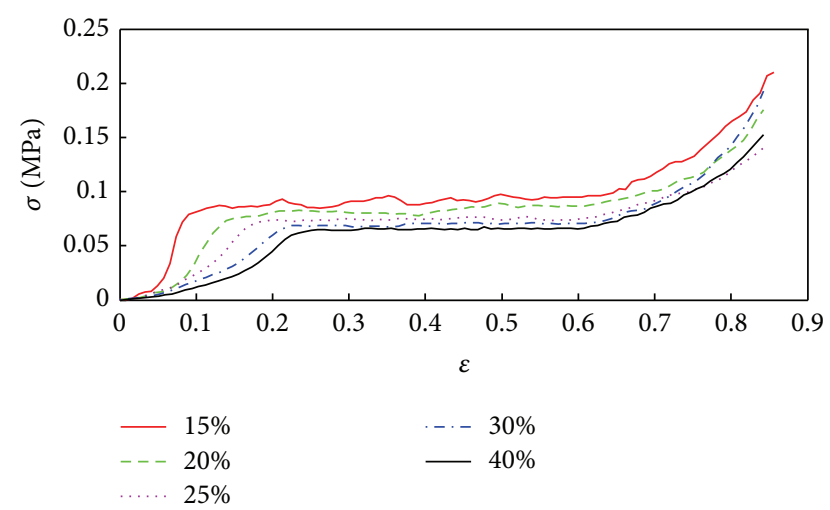

(b)

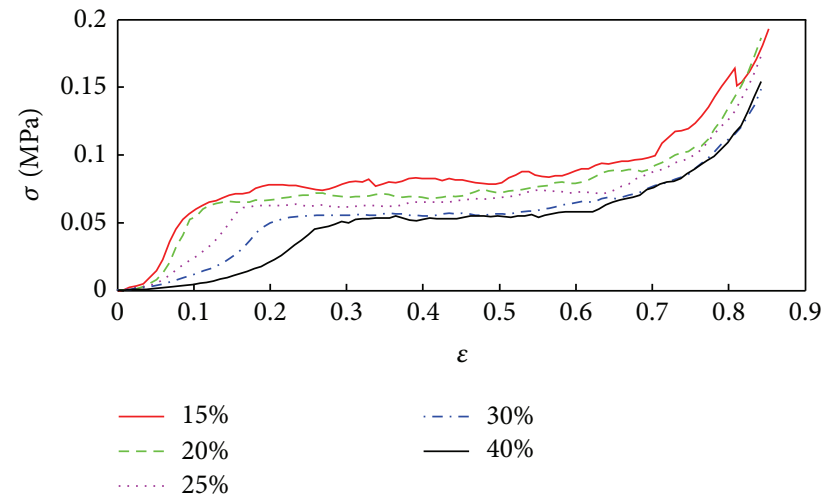

(d)

FIGURE 2: Effect of fatigue stress-strain relationship of various precompression honeycomb paperboard $(t / l=0.0263)(\mathrm{a}) n=10000,(\mathrm{~b})$ $n=20000$, (c) $n=30000$, and (d) $n=50000$.

TABLE 4: Plateau stress of honeycomb paperboard $(t / l=0.0263)$ under various precompression $\left(23^{\circ} \mathrm{C}\right)$.

\begin{tabular}{|c|c|c|c|c|c|}
\hline \multirow{2}{*}{$n$} & \multicolumn{5}{|c|}{ Plateau stress (MPa) } \\
\hline & $\varepsilon=15 \%$ & $\varepsilon=20 \%$ & $\varepsilon=25 \%$ & $\varepsilon=30 \%$ & $\varepsilon=40 \%$ \\
\hline$n=10000$ & 0.1063 & 0.0918 & 0.0834 & 0.0768 & 0.0733 \\
\hline$n=20000$ & 0.0945 & 0.0825 & 0.0741 & 0.0698 & 0.0645 \\
\hline$n=30000$ & 0.0835 & 0.0732 & 0.0672 & 0.0612 & 0.0575 \\
\hline$n=50000$ & 0.0786 & 0.0674 & 0.0614 & 0.0574 & 0.0548 \\
\hline
\end{tabular}

According to Figure 3 the efficiency curve goes through a maximum but for each honeycomb paperboard this max point is attained at a different stress. Efficiency of energy absorption changes steeply from $n=0$ to 30000 but decreases slightly when $n=30000$ to 50000 .

Energy absorption per unit volume of three kinds of honeycomb paperboards under five levels of FD is calculated by (2). The results are listed in Table 5 :

$$
W=\int_{0}^{\varepsilon_{D}} \sigma d \varepsilon
$$

It can be seen that energy absorption per unit volume of honeycomb paperboard decreases with FD increasing. The relationship between the energy absorption per unit volume of honeycomb paperboard with the same $t / l$ value and the
FD can be divided into two phases: the energy absorption per unit volume has the large fluctuations FD from $n=0$ to 30000 , while it decreases slightly with FD from $n=30000$ to 50000 .

Since FD has no significant effect on densification strain of honeycomb paperboard, the energy absorption per unit volume under different levels of FD is dependent on plateau stress.

The relationship between the energy absorption per unit volume and $\mathrm{FD}$ can also be characterized by the energy absorption curves by running MATLAB programs (Figure 4). It can be seen that inflections of energy absorption curves shift to the lower left corner with the increasing of FD from $n=0$ to 30000 , but they are about the same when $n=30000$ to 50000. It suggests a weakening of load carrying property and energy absorption capacity of honeycomb paperboard 


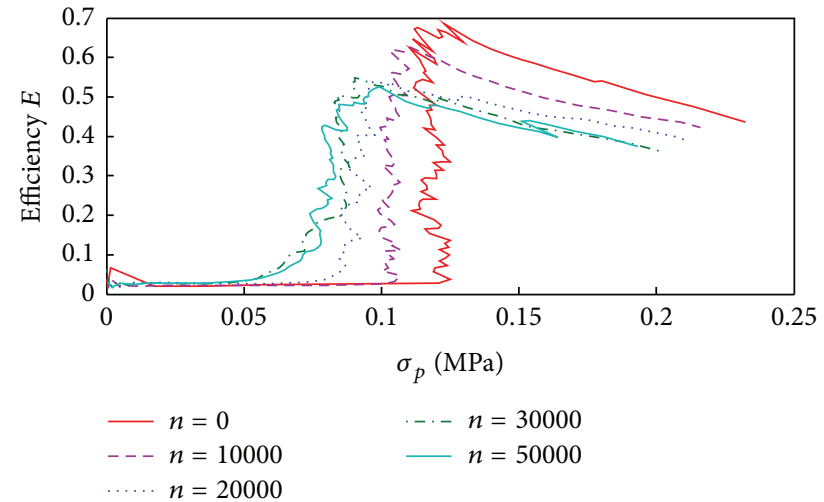

(a)

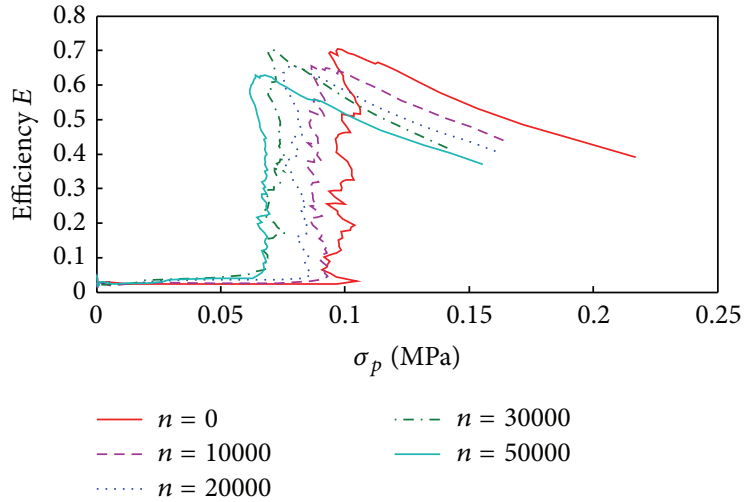

(b)

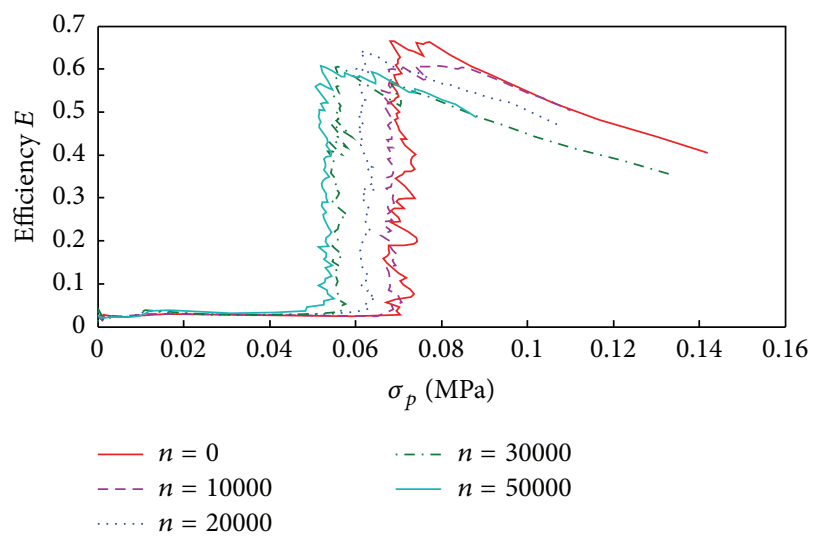

(c)

Figure 3: Energy absorption efficiency curves of honeycomb paperboards with different $t / l$ value in various $\mathrm{FD}\left(23^{\circ} \mathrm{C}\right)$. (a) $t / l=0.0263$; (b) $t / l=0.0238 ;(c) t / l=0.0219$.

TABLE 5: Energy absorption per unit volume of paper honeycomb under various FD $\left(23^{\circ} \mathrm{C}\right)$.

\begin{tabular}{|c|c|c|c|c|c|}
\hline \multirow{2}{*}{$\begin{array}{l}\text { Thickness-to-length } \\
\text { ratio } t / l\end{array}$} & \multicolumn{5}{|c|}{ Energy absorption per unit volume $W\left(\mathrm{~J} \mathrm{~cm}^{-3}\right)$} \\
\hline & $n=0$ & $n=10000$ & $n=20000$ & $n=30000$ & $n=50000$ \\
\hline 0.0263 & 0.0855 & 0.0741 & 0.0661 & 0.0577 & 0.0572 \\
\hline 0.0238 & 0.0712 & 0.0624 & 0.0570 & 0.0491 & 0.0460 \\
\hline 0.0219 & 0.0511 & 0.0497 & 0.0448 & 0.0411 & 0.0384 \\
\hline
\end{tabular}

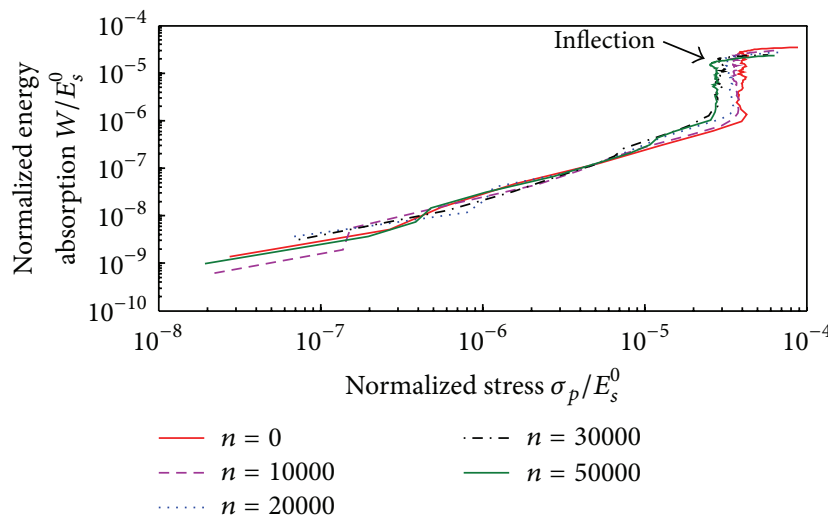

Figure 4: Energy absorption curves $(t / l=0.0263)$. after FD. $E_{s}^{0}$ is the elastic modulus of corrugated medium $\left(E_{s}^{0}=2.223 \mathrm{GPa}\right)$.

Figure 5 shows the energy absorption efficiency curves of various precompressed honeycomb paperboard in different $\mathrm{FD}(t / l=0.0263)$. According to Figure 5, efficiency of energy absorption changes steeply by precompression.

Energy absorption per unit volume of paper honeycomb under various precompression is calculated by (2). The results are listed in Table 6.

It can be seen that energy absorption per unit volume of honeycomb paperboard decreases with precompression increasing. The relationship between the energy absorption per unit volume of honeycomb paperboard under various precompression and the FD can be divided into two 


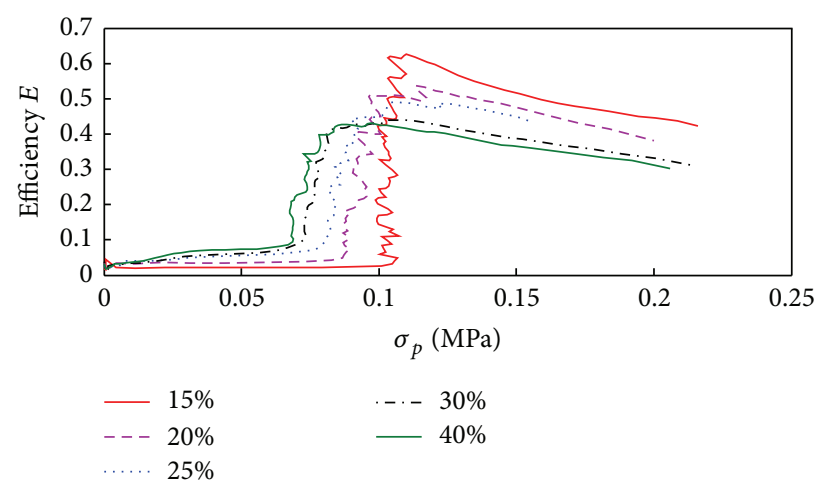

(a)

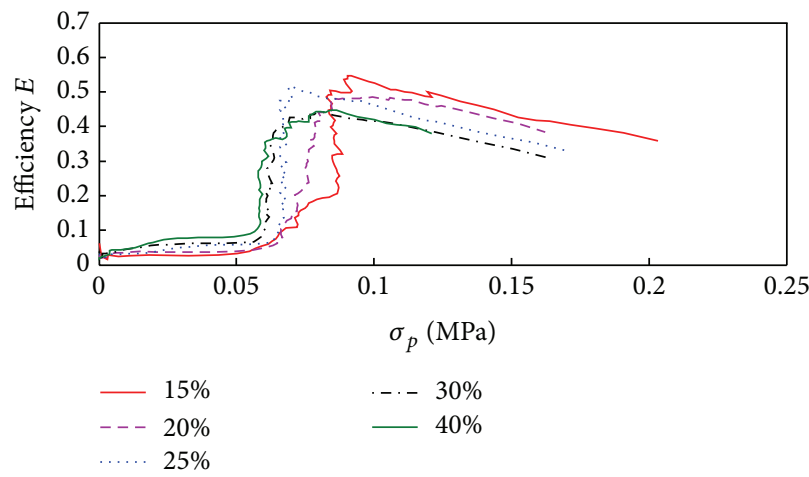

(c)

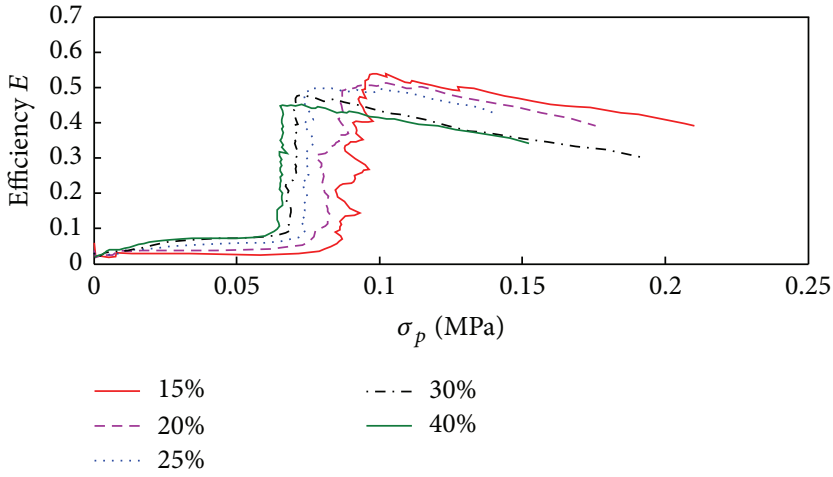

(b)

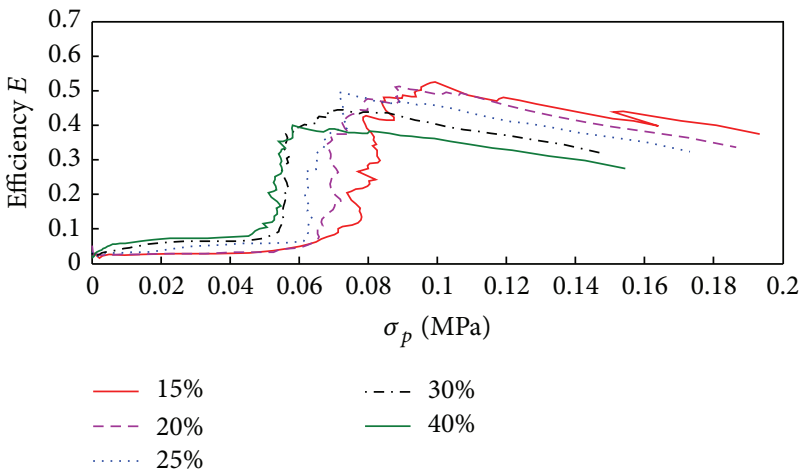

(d)

FIGURE 5: Energy absorption efficiency curves of various precompressed honeycomb paperboard in different FD $(t / l=0.0263)(\mathrm{a}) n=10000$, (b) $n=20000$, (c) $n=30000$, and (d) $n=50000$.

TABLE 6: Energy absorption per unit volume of paper honeycomb under various precompression $\left(23^{\circ} \mathrm{C}\right)$.

\begin{tabular}{|c|c|c|c|c|c|}
\hline \multirow{2}{*}{$n$} & \multicolumn{5}{|c|}{ Energy absorption per unit volume $W\left(\mathrm{~J} \mathrm{~cm}^{-3}\right)$} \\
\hline & $\varepsilon=15 \%$ & $\varepsilon=20 \%$ & $\varepsilon=25 \%$ & $\varepsilon=30 \%$ & $\varepsilon=40 \%$ \\
\hline$n=10000$ & 0.0741 & 0.0631 & 0.0560 & 0.0525 & 0.0486 \\
\hline$n=20000$ & 0.0661 & 0.0565 & 0.0496 & 0.0453 & 0.0413 \\
\hline$n=30000$ & 0.0577 & 0.0511 & 0.0449 & 0.0401 & 0.0371 \\
\hline$n=50000$ & 0.0572 & 0.0508 & 0.0446 & 0.0373 & 0.0324 \\
\hline
\end{tabular}

phases: the energy absorption per unit volume has the large fluctuations FD from $\varepsilon=15 \%$ to $\varepsilon=25 \%$, while it decreases slightly from $\varepsilon=25 \%$ to $\varepsilon=40 \%$. For example, the energy absorption per unit volume $(n=10000)$ decreased by $24.42 \%$ from $\varepsilon=15 \%$ to $\varepsilon=25 \%$ but decreased by $13.21 \%$ from $\varepsilon=$ $25 \%$ to $\varepsilon=40 \%$. Above all, precompression has significant effect on the energy absorption of honeycomb paperboard.

Figure 6 shows energy absorption curves by running MATLAB programs. It can be seen that the fatigue damage has much significant effect on energy absorption after precompression. The inflections of energy absorption curves shift rapidly to the lower left corner with the increasing of precompression from $\varepsilon=15 \%$ to $\varepsilon=25 \%$, but they have little fluctuations with the increasing of precompression from $\varepsilon=25 \%$ to $\varepsilon=40 \%$.

\section{Conclusions}

Responses of honeycomb paperboard with different values of thickness-to-length ratio under different levels of FD were studied in this paper. The experimental results suggest that the effect of FD on the mechanical behavior and the energy absorption properties of honeycomb paperboard were elucidated.

The plateau stress and FD can be divided into two stages demarcated by $n=30000$. The plateau stress is sensitive to FD from $n=0$ to 30000 and FD has no significant effect on plateau stress from $n=30000$ to 50000 . FD has no significant effect on the densification strains.

Efficiency of energy absorption changes steeply from $n=$ 0 to 30000 but decreases slightly when $n=30000$ to 50000 . 


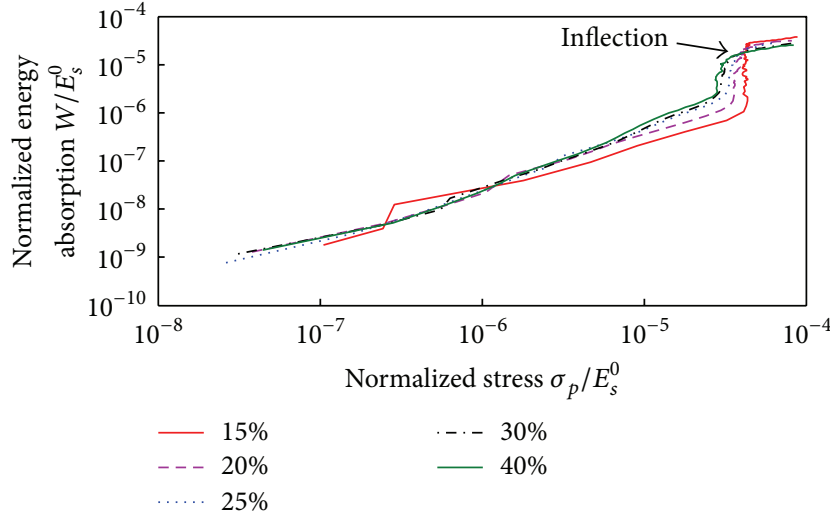

FIGURE 6: Energy absorption curve $(t / l=0.0263) n=10000$.

The energy absorption per unit volume has the large fluctuations FD from $n=0$ to 30000 , while it decreases slightly with FD from $n=30000$ to 50000 . Inflections of energy absorption curves shift to the lower left corner with the increasing of FD from $n=0$ to 30000 , but they are about the same when $n=30000$ to 50000 .

The plateau stress is sensitive to precompression from $\varepsilon=$ $15 \%$ to $\varepsilon=25 \%$ and FD has slight effect on plateau stress from $\varepsilon=25 \%$ to $\varepsilon=40 \%$. Precompression has no significant effect on the densification strains.

The fatigue damage has much significant effect on energy absorption after precompression.

Efficiency of energy absorption changes steeply by precompression. The inflections of energy absorption curves shift rapidly to the lower left corner with the increasing of precompression from $\varepsilon=15 \%$ to $\varepsilon=25 \%$, but they have little fluctuations with the increasing of precompression from $\varepsilon=$ $25 \%$ to $\varepsilon=40 \%$.

\section{Conflict of Interests}

The authors declare that there is no conflict of interests in the research.

\section{Acknowledgment}

This work was supported by Fundamental Research Funds for the Central Universities (Grant no. JUSRP51403A).

\section{References}

[1] S. K. Maiti, L. J. Gibson, and M. F. Ashby, "Deformation and energy absorption diagrams for cellular solids," Acta Metallurgica, vol. 32, no. 11, pp. 1963-1975, 1984.

[2] D.-M. Wang and Z.-W. Wang, "Experimental investigation into the cushioning properties of honeycomb poperboord," Packaging Technology and Science, vol. 21, no. 6, pp. 309-316, 2008.

[3] Z.-W. Wang and Y. P. E, "Mathematical modelling of energy absorption property for paper honeycomb in various ambient humidities," Materials and Design, vol. 31, no. 9, pp. 4321-4328, 2010.
[4] J. Wang and L. X. Lu, "Energy-absorption diagrams of honeycomb paperboards under static compression in different relative humidity," Packaging Engineering, vol. 32, no. 1, pp. 5-7, 2011.

[5] E. Yuping, "Energy absorption properties of paper-based packaging materials as response to various ambient humidities," Applied Mechanics and Materials, vol. 200, pp. 155-159, 2012.

[6] Y. Guo and J. Zhang, "Shock absorbing characteristics and vibration transmissibility of honeycomb paperboard," Shock and Vibration, vol. 11, no. 5-6, pp. 521-531, 2004.

[7] J. Wang, Z.-W. Wang, L.-X. Lu, Y. Zhu, and Y.-G. Wang, "Three-dimensional shock spectrum of critical component for nonlinear packaging system," Shock and Vibration, vol. 18, no. 3, pp. 437-445, 2011.

[8] A.-J. Chen, "The shock characteristics of tilted support spring packaging system with critical components," Shock and Vibration, vol. 2014, Article ID 496035, 8 pages, 2014.

[9] L. Hou-Min, L. Chen-Hua, and X. Yi-Kui, "Effect of preload on the cushioning performance of honeycomb paperboard," Packaging Engineering, vol. 28, no. 6, pp. 44-46, 2007 (Chinese).

[10] B.-S. Wang and L. Zhang, "Research on cushioning performance of honeycomb paperboard under the second load," Packaging Engineering, vol. 32, no. 15, pp. 62-65, 2011 (Chinese).

[11] H. Wang, W.-M. Wang, B.-L. Hu, and X.-Z. Zhang, "Effective cushioning of paper honeycomb material and pre-compression test," Packaging Engineering, vol. 33, no. 1, pp. 20-23, 2012 (Chinese).

[12] J. J. Sun, "Research on fatigue damage curve of corrugated cardboard," Packaging Engineering, vol. 29, no. 12, pp. 4-10, 2008 (Chinese).

[13] J. J. Sun and L. Li-xin, "Study of fatigue vibration effect on corrugated fiberboard based on residual strength model," Packaging Engineering, vol. 28, no. 8, pp. 19-21, 2007.

[14] V. Rouillard, M. Lamb, and M. A. Sek, "Determining fatigue progression in corrugated paperboard containers subjected to dynamic compression," in Proceedings of the 5th Australasian Congress on Applied Mechanics, pp. 331-336, 2007.

[15] M. J. Lamb, V. Rouillard, and M. A. Sek, "Monitoring the evolution of damage in packaging systems under sustained random loads," Packaging Technology and Science, vol. 25, no. 1, pp. 39-51, 2012.

[16] Z.-g. Fan and L.-x. Lu, "Effect of fatigue damage on innerresonance conditions of precompressed honeycomb paperboard system," Advances in Mechanical Engineering, vol. 2014, Article ID 817404, 4 pages, 2014.

[17] GB8168, "Testing Method of Static Compression for Package Cushioning Materials," (Chinese).

[18] E. Yu Ping and Z. W. Wang, "Effect of relative humidity on energy absorption properties of honeycomb paperboards," Packaging Technology and Science, vol. 23, no. 8, pp. 471-483, 2010. 

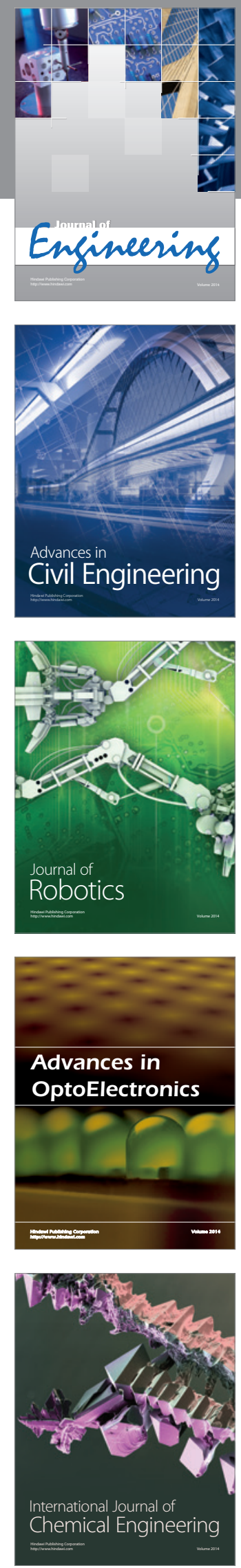

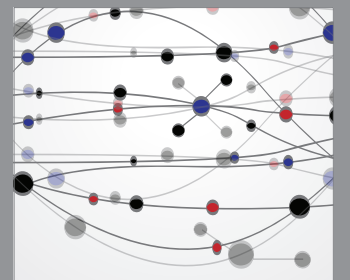

The Scientific World Journal
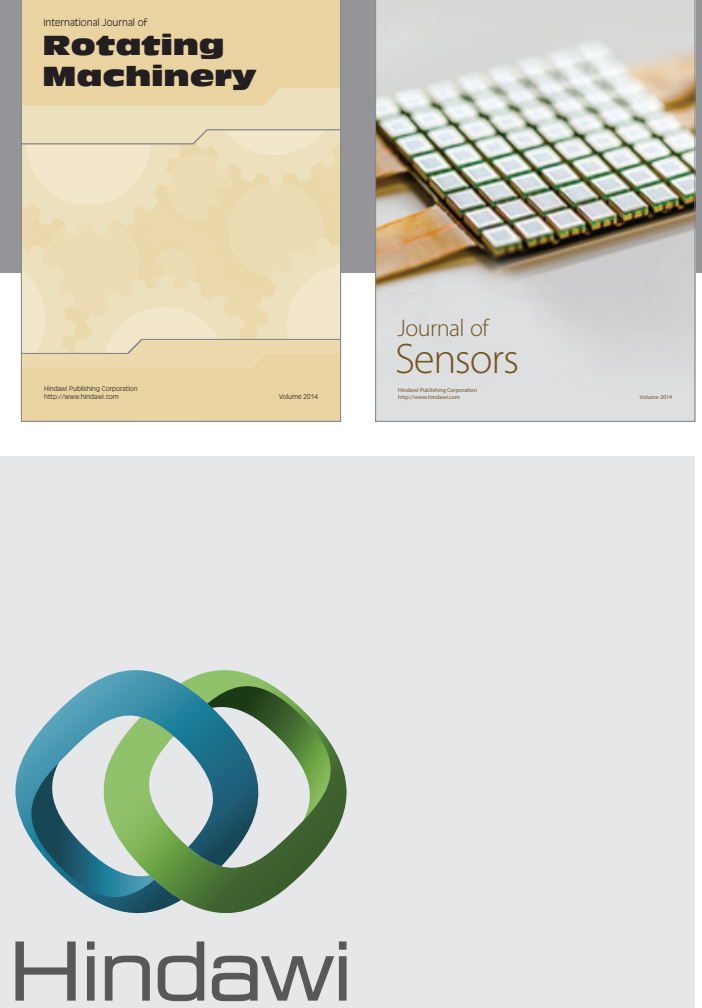

Submit your manuscripts at http://www.hindawi.com
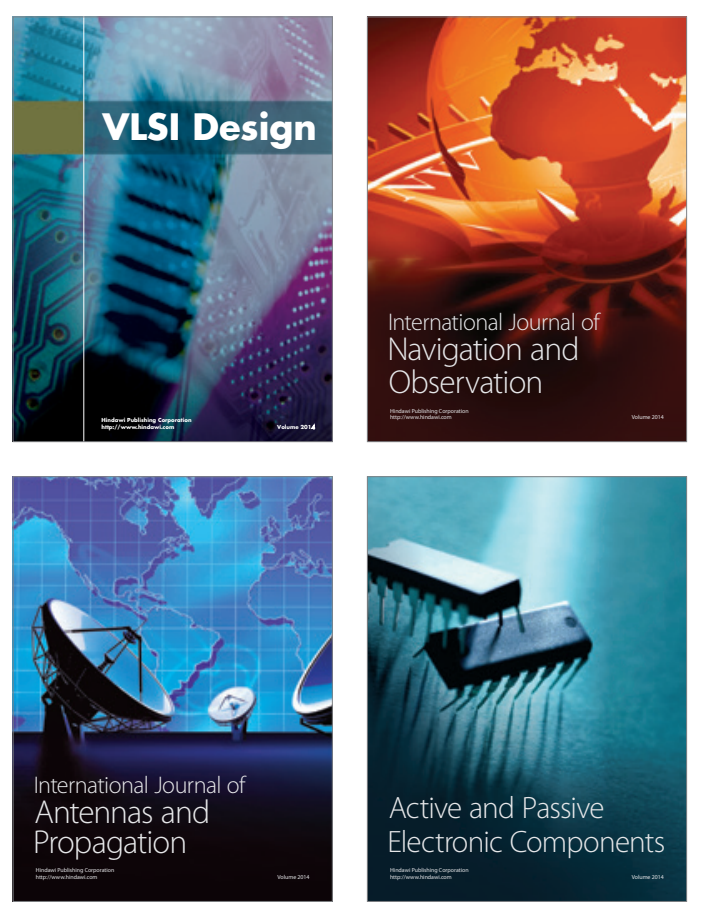
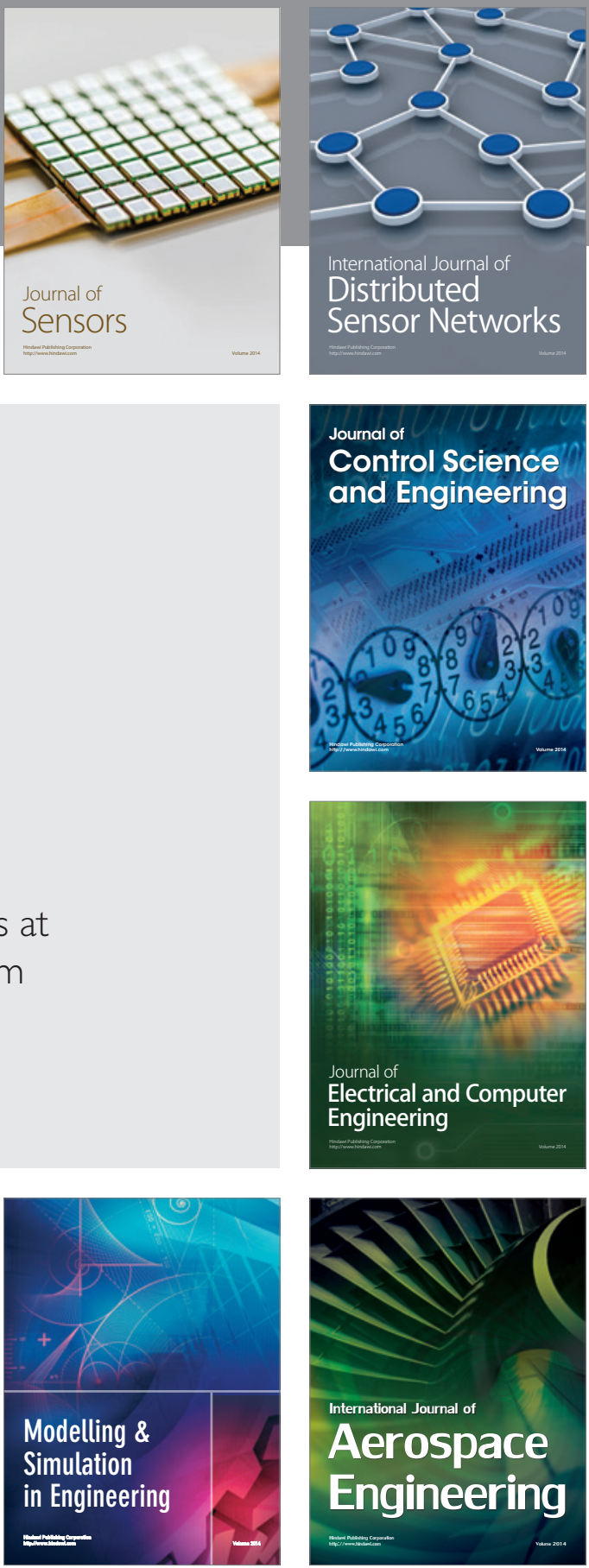

Journal of

Control Science

and Engineering
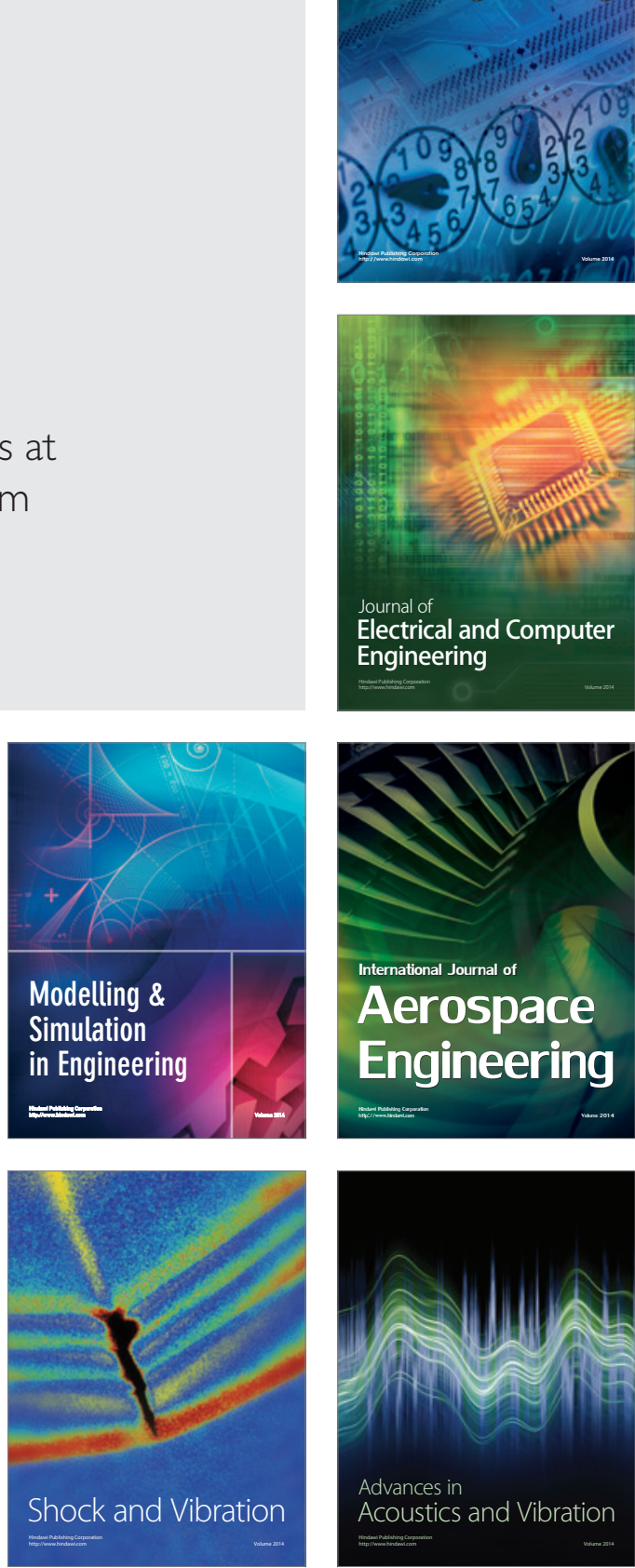